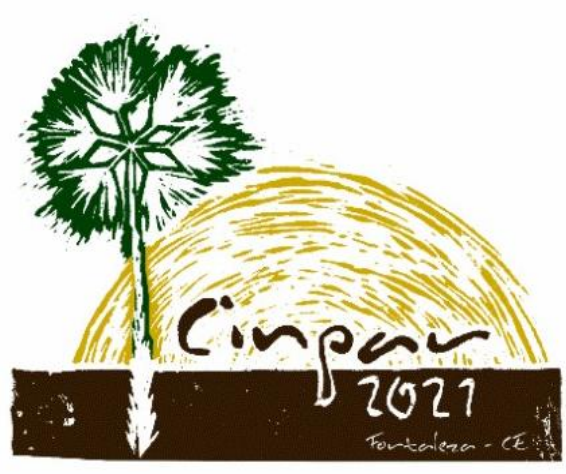

XVII Congresso Internacional sobre Patologia e Reabilitação das Construções

XVII Congreso Internacional sobre Patología y Rehabilitación de las Construcciones

XVII International Conference on Pathology and Constructions Rehabilitation

FORTALEZA (Brasil), 3 a 5 de junho de 2021 https://doi.org/10.4322/CINPAR.2021.068

\title{
Bambusa Vulgaris: caracterização das propriedades mecânicas do bambu cultivado em Redenção, Ceará-Brasil
}

\section{Bambusa Vulgaris: characterization of the mechanical properties of bamboo grown in Redenção, Ceará-Brazil}

\author{
Wanner Kelly DAMASCENO DA SILVA', Tallis Deyvide MAIA RUBENS², Antônio Eduardo BEZERRA CABRAL ${ }^{3}$ \\ ${ }^{1}$ Universidade Federal do Ceará UFC, Fortaleza, Brasil, kellydamasc@gmail.com1 \\ ${ }^{2}$ Universidade Federal do Ceará UFC, Fortaleza, Brasil, tallis.maia@gmail.com2 \\ ${ }^{3}$ Universidade Federal do Ceará UFC, Fortaleza, Brasil, eduardo.cabral@ufc.br3
}

\begin{abstract}
Resumo
O bambu possui elevado potencial de aplicação na construção civil em substituição parcial ou total aos materiais convencionais, tais como concreto, madeira e aço. A utilização do bambu abrange elementos que compõem as edificações, sejam estruturais, como pilares, vigas e lajes, ou arquitetônicos, mesclando funções mecânicas à estética. Porém, o escasso conhecimento e a deficiência no uso do bambu de espécie Bambusa Vulgaris na construção civil brasileira evidenciam a emergente busca por estudos sobre o tema. $O$ presente artigo tem como objetivo analisar as características mecânicas do bambu de espécie Bambusa Vulgaris, extraído de três regiões distintas do colmo maduro cultivado no município de Redenção, Ceará, Brasil. Foram realizados ensaios de resistência à compressão e resistência ao cisalhamento paralela às fibras, tendo em vista a importância destas propriedades no dimensionamento de estruturas. Os resultados de caracterização mecânica demonstram o potencial do bambu aplicado à construção civil, sendo obtidos valores de resistência à compressão média de $37,3 \mathrm{MPa}$ e resistência ao cisalhamento médio na ordem de $3,9 \mathrm{MPa}$, comparativos ao concreto convencional com resistência à compressão de $32,0 \mathrm{MPa}$ e resistência ao cisalhamento de 7,0 MPa.
\end{abstract}

Palavras-chave: Caracterização; Material Alternativo; Bambu; Propriedades mecânicas.

\begin{abstract}
Bamboo has a high potential for application in civil construction in partial or total replacement to conventional materials, such as concrete, wood and steel. The use of bamboo covers elements that make up the buildings, be structural, such as pillars, beams and slabs, or architectural, mixing mechanical functions with aesthetics. However, the scarce knowledge and the deficiency in the use of bamboo of the Bambusa Vulgaris species in Brazilian civil construction evidence the emerging search for studies on the subject. This paper aims to analyze the mechanical characteristics of Bambusa Vulgaris bamboo, extracted from three distinct regions of the mature stem grown in the municipality of Redenção, Ceará, Brazil. Compressive strength and shear strength tests were carried out parallel to the fibers, in view of the importance of these properties in the design of structures. The results of mechanical characterization demonstrate the potential of bamboo applied to civil construction, obtaining values of average compressive strength of $37.3 \mathrm{MPa}$ and average shear strength in the order of $3.9 \mathrm{MPa}$, compared to conventional concrete with compressive strength of 32.0 MPa and shear strength of 7.0 MPa.
\end{abstract}

Keywords: Characterization; Alternative material; Bamboo; Mechanical properties. 


\section{Introdução}

O bambu está presente em diversas regiões do mundo, sendo utilizado para inúmeras finalidades, que vão desde o seu emprego na área farmacêutica até a execução de projetos sustentáveis nas áreas de engenharia e arquitetura. Segundo a Organização Internacional de Bambu e Rattan (Inbar), 60 bilhões de dólares é o montante que o bambu movimenta anualmente em todo o mundo. Os maiores produtores são a China, o Brasil e a Índia.

A China, líder na produção mundial de bambu, tem uma vasta lista de utilidades da planta, cerca de 1500 aplicações. Compõem essa lista o seu emprego em projetos de irrigação, paisagismo e artesanato, bem como o aproveitamento na culinária, na produção de papel, carvão, móveis e em projetos de engenharia e arquitetura (RIBAS, 2015). Na Índia, é utilizado como matéria-prima para celulose. O papel feito de Bambusa Vulgaris tem excepcional resistência ao rasgo, comparável ao papel feito de madeira macia. Também pode ser usado para fazer painéis de partículas e papel de grau de embalagem flexível.

No território brasileiro, o bambu é cultivado principalmente nas regiões nordeste e sudeste do país. No estado do Maranhão, a sua produção é destinada para a geração de energia através da biomassa. Nos estados de Pernambuco e Paraíba, o bambu é utilizado na produção de celulose e papel, já a produção de painéis, broto e fitocosméticos, se concentram nos estados de São Paulo, Minas Gerais, Bahia, Paraná e Rio Grande do Sul (EMBRAPA, 2018).

No Brasil existem cerca de 260 espécies de bambus nativos. Os bambus dos gêneros Guadua e Merostachys se destacam pelo elevado interesse econômico e por estarem presentes em grande parte do território nacional, se tornando os principais tipos de bambus nativos do país. No entanto, outras espécies de considerável potencial econômico foram importadas pelos colonizadores portugueses e pelos imigrantes japoneses, como os bambus dos gêneros Phyllostachys e Bambusa.

A propagação do bambu pode ocorrer de duas formas: vegetativa e assexuada. A primeira pode ser realizada através do colmo, dos rizomas e dos ramos laterais (galhos), onde um dos benefícios principais é a geração de clones, mantendo assim as características fenotípicas idênticas à mãe (SILVA; LIMA; OLIVEIRA, 2011). Por sua vez, a segunda forma de propagação ocorre devido à rebentação das raízes, ou através da combinação com raízes vizinhas (SILVA, 1985).

Por apresentar cultivo fácil e de baixo custo, crescimento rápido, elevada produtividade por hectare, baixa densidade, alta resistência à tração e compressão, e baixa energia de produção, o bambu e a sua madeira tornaram-se alternativas sustentáveis aos materiais convencionais que compõem os projetos de engenharia e arquitetura. Por essas e outras características, o bambu possui elevado potencial de aplicação na construção civil, em especial nos elementos que compõem as edificações, sejam eles estruturais, como: pilares, vigas e lajes, ou arquitetônicos, mesclando funções mecânicas à estética da planta. No entanto, quando utilizado em projetos estruturais, é fortemente recomendada a aplicação de tratamentos preventivos, pois como todo material biológico, o bambu está suscetível à deterioração natural (GHAVAMI E TOLEDO FILHO, 1992).

O bambu, como material alternativo em substituição parcial ou total aos convencionais da construção civil, como: o concreto, a madeira e o aço; pode contribuir para a redução da emissão do gás carbônico na atmosfera, para a diminuição do desmatamento de florestas virgens e para a redução da geração de resíduos sólidos (PADOVAN, 2010).

Dessa forma, evidencia-se a importância em aprofundar os estudos em torno do bambu e suas aplicações nessa área. A ausência de conhecimento acadêmico sobre as potencialidades da espécie Bambusa Vulgaris, a sua escassa utilização na construção civil e a sua alta oferta na região de aplicação deste projeto, são fatores que fortalecem a necessidade de conhecer e caracterizar essa espécie, com o objetivo de difundir a sua aplicação e com isso expandir a economia local.

O presente estudo tem por objetivo caracterizar o bambu de espécie Bambusa Vulgaris quanto às propriedades mecânicas de resistência à compressão e ao cisalhamento paralelo às fibras. Foram investigadas as diferenças entre os valores das propriedades mencionadas em diferentes posições do colmo (Base, Intermédio e Topo) e na presença ou ausência de nós, visando indicar a utilização do bambu B. Vulgaris como material alternativo para construção civil. 


\section{Materiais e Métodos}

\subsection{Bambusa Vulgaris}

Este estudo envolve a utilização do bambu típico do estado do Ceará no Brasil, cuja classe é designada como Monocotiledônea, ordem Poales, família Poaceae, subfamília Bambusoide, tribo Bambuseae (Bambus Lenhosos), gênero Bambusa e espécie B. Vulgaris. Todos os colmos de bambu testados foram cultivados em Redenção, município localizado nas coordenadas de Latitude $4^{\circ} 13^{\prime}$ 35" Sul, Longitude $38^{\circ} 43^{\prime} 53^{\prime \prime}$ Oeste e altitude de 92 m, cujo clima é Tropical Quente Úmido, caracterizado por altas temperaturas e elevada umidade, favorável ao desenvolvimento desta espécie de bambu.

Os colmos da espécie Bambusa Vulgaris apresentam altura média de 10 metros a 20 metros, diâmetro entre $4 \mathrm{~cm}$ a $10 \mathrm{~cm}$, estrutura ereta próxima à base e encurvada ao longo do topo (CASTELO BRANCO, 2016), conforme Figura 1. Em um bambuzal existe elevada diversidade de maturação das touceiras, havendo colmos jovens, identificado pela coloração verde intensa e pela presença de brácteas, e maduros em diferentes idades, estes apresentando manchas ao longo dos colmos e livres de brácteas.

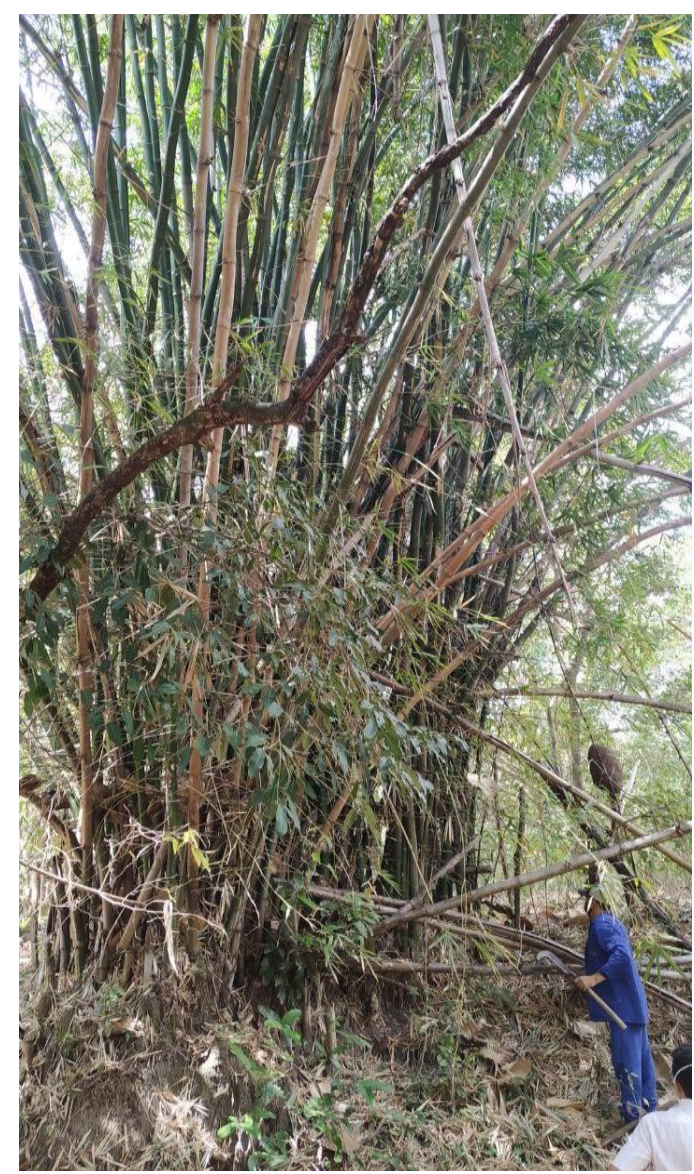

Figura 1 - Bambuzal da espécie Bambusa Vulgaris

A seleção dos colmos de bambu foi realizada a partir de amostras representativas da área de cultivo e com idade média entre 3 (três) a 5 (cinco) anos de plantação no município de Redenção, estado do Ceará Brasil. Foram utilizadas foices para corte dos colmos de bambu, a uma altura média de corte a partir de 30 cm (um entrenó) do solo. Após descarte da parte superior não utilizável dos colmos, foram obtidas varas com tamanho aproximado de 3 (três) metros, sendo estas divididas em 3 (três) partes iguais: Basal (B), Intermédio (I) e Topo (T).

Foram coletadas varas de bambu maduras e livres de defeitos aparentes, apresentando maior rigidez dos colmos. Para identificação das varas maduras, observou-se a ausência de brácteas; a presença de manchas externas; o aspecto envelhecido e a posição da touceira, normalmente ao centro do bambuzal e com acesso dificultado. 
Após coleta, as varas foram abrigadas em local livre de intempéries (como chuva e raios solares) e posicionadas na vertical para secagem natural ao ar.

As varas de bambu foram cortadas no equipamento Serra de bancada (Corrupio) com disco de corte apropriado para madeira, conforme dimensões especificadas em cada ensaio. Devido aos desvios médios de planicidade das amostras cilíndricas, após o corte, resultarem em valores superiores a $0,20 \mathrm{~mm}$, limite preconizado pela NBR 16828-2:2019, fez-se necessário o capeamento dos corpos de prova em bambu com massa adesiva de base epóxi composta por sulfato de bário, silicato de alumínio e dióxido de titânio, conferindo a planicidade adequada ao material, conforme Figura 2.
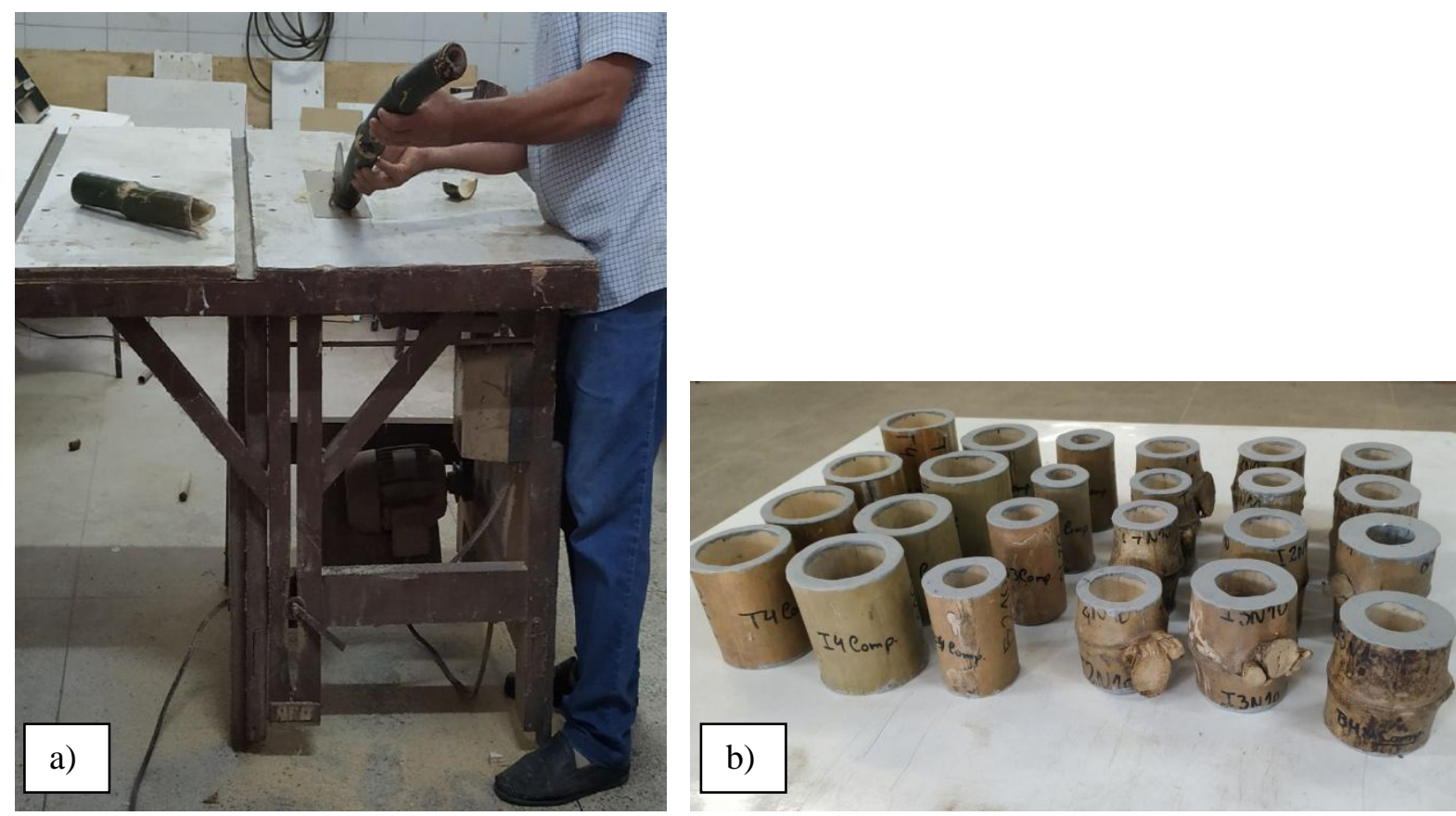

Figura 2 - a) Corte do colmo para confecção dos corpos de prova; b) Amostras após capeamento para ensaios de compressão e cisalhamento paralelo às fibras

\subsection{Análise das propriedades mecânicas do bambu}

Foram realizados os ensaios de caracterização mecânica do bambu da espécie Bambusa Vulgaris conforme descrito no Quadro 1.

Quadro 1 - Caracterização mecânica do Bambusa Vulgaris

\begin{tabular}{|c|c|c|c|c|}
\hline Determinação & Método & Equipamento & Amostragem & Dimensões (mm) \\
\hline $\begin{array}{c}\text { Resistência à } \\
\text { compressão } \\
\text { paralela às fibras }\end{array}$ & $\begin{array}{c}\text { ISO 22157:2019/ } \\
\text { NBR 16828-2 }\end{array}$ & $\begin{array}{c}\text { Máquina } \\
\text { Universal de } \\
\text { Ensaios }\end{array}$ & 24 unidades & $100 \times \mathrm{D} \times \mathrm{t}^{*}$ \\
\hline $\begin{array}{c}\text { Resistência ao } \\
\text { cisalhamento } \\
\text { paralelo } \\
\text { às fibras }\end{array}$ & $\begin{array}{c}\text { Máquina } \\
\text { ISO 22157:2019/ }\end{array}$ & $\begin{array}{c}\text { Universal de } \\
\text { Ensaios / } \\
\text { Placas de } \\
\text { Cisalhamento }\end{array}$ & 24 unidades & $100 \times \mathrm{D} \times \mathrm{t}^{*}$ \\
\hline
\end{tabular}

Nota: D: diâmetro externo; t: espessura da parede do colmo

A amostragem de corpos de prova foi dividida entre as regiões basal, intermédio e topo, com e sem nó, havendo a distribuição das amostras em 6 (seis) grupos nomeados B, I, T, BN, IN, TM (Basal sem nó, Intermédio sem nó, Topo sem nó, Basal com nó, Intermédio com nó e Topo com nó, respectivamente). 
Para o ensaio de Resistência à compressão paralela às fibras, segundo NBR 16828-2:2019, Figura 3, a amostra foi colocada centralizada na máquina de ensaios. Para acomodação do corpo de prova, uma pequena carga (não superior a $1 \mathrm{kN}$ ) foi inicialmente aplicada e relaxada. Durante o ensaio, 0 carregamento foi aplicado continuamente, de forma que a placa móvel da máquina de ensaio apresentou uma velocidade constante de, aproximadamente, $0,01 \mathrm{~mm} / \mathrm{s}$. Foi registrada a carga máxima medida pelo equipamento de ensaio.

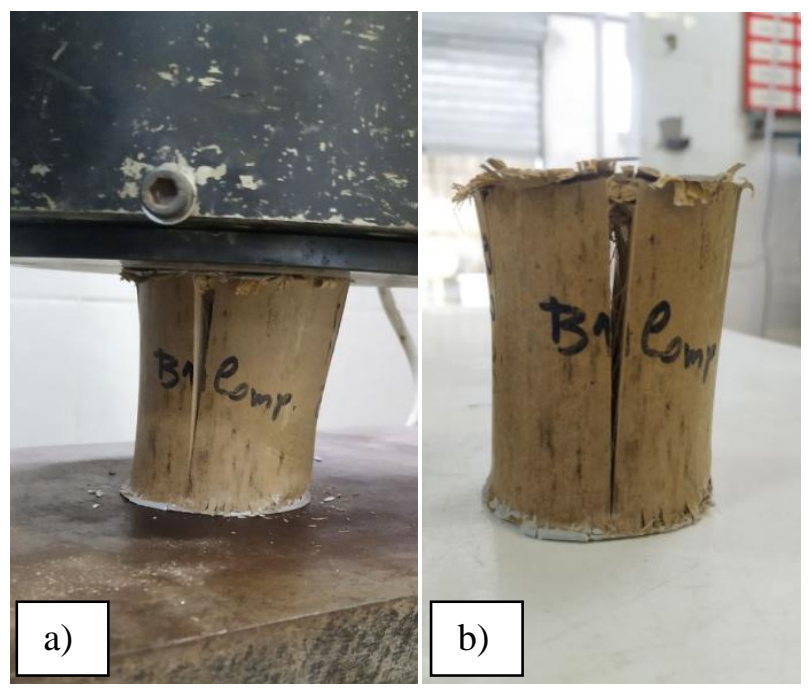

Figura 3 - Amostras durante (a) e após (b) ensaio de Resistência à compressão parela às fibras

Conforme NBR 16828-2:2019 - Estruturas de bambu Parte 2: Determinação das propriedades físicas e mecânicas do bambu, foi realizado ensaio de resistência ao cisalhamento paralelo às fibras onde o corpo de prova foi apoiado na extremidade inferior em chapas rígidas ao longo de dois quartos, uma em frente da outra, e carregado na extremidade superior ao longo dos dois quartos que não são apoiados, conforme a Figura 4. Desta forma têm-se quatro áreas de cisalhamento ensaiados em máquina de compressão, sem dispositivo de redução de atrito.
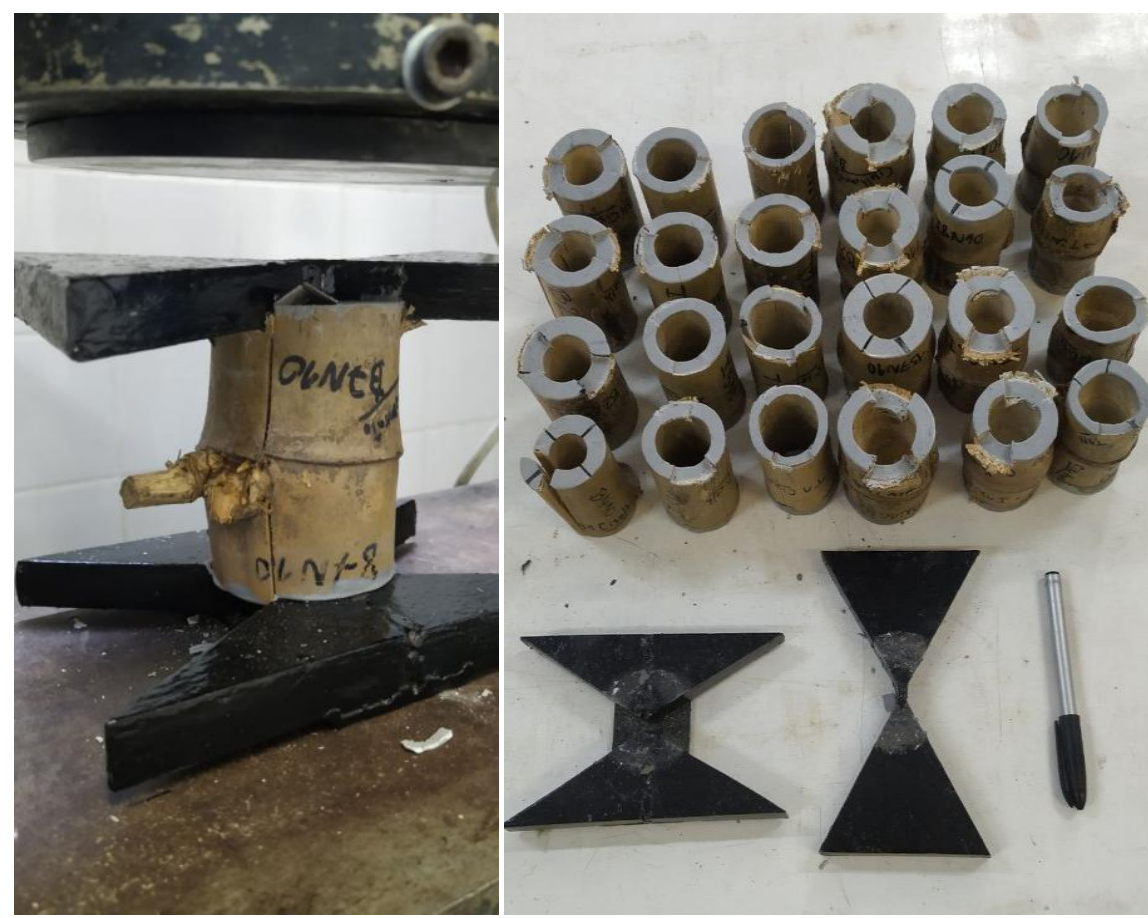

Figura 4 - Amostras após ensaio de Resistência ao Cisalhamento paralelo às fibras, evidenciando as chapas rígidas utilizadas

B. Vulgaris: caracterização das propriedades mecânicas do bambu cultivado em Redenção, Ceará-Brasil 


\section{Apresentação e discussão dos resultados}

A Figura 5 apresenta o gráfico de Tensão à Compressão em relação à Deformação longitudinal para amostras sem nó, onde se observam maiores valores de tensão à compressão e deformações para a região do topo, obtendo-se valor máximo de tensão média igual a 48,2 MPa. Houve queda gradual para os valores de tensão e deformação no sentido Topo-Base, constatando-se resistência à compressão média de 42,5 MPa para a região intermediária e 37,0 MPa para a posição basal conforme Tabela 1.

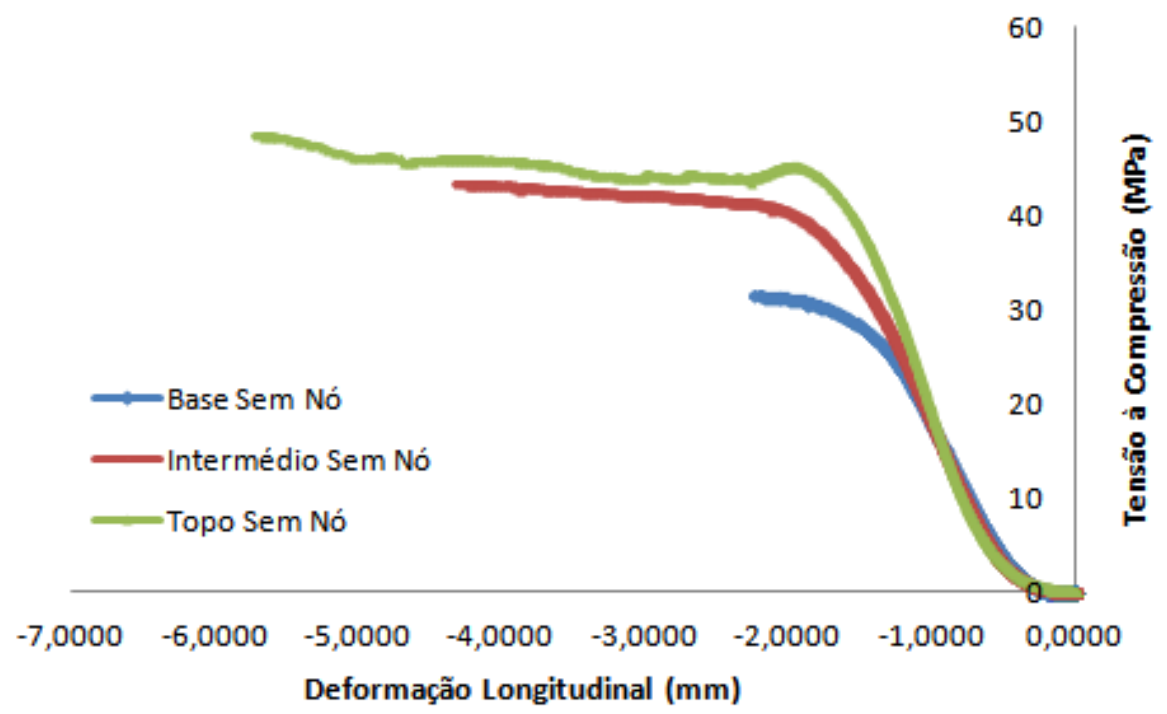

Figura 5 - Gráfico Tensão à Compressão x Deformação longitudinal (Amostras Sem Nó)

O gráfico de Tensão à Compressão em relação à Deformação longitudinal para amostras com nó é apresentado na Figura 6, onde se observam maiores valores de tensão à compressão e deformações para a região do intermédio, obtendo-se valor máximo de tensão média igual a 33,4 MPa. Constatou-se resistência à compressão média de 32,5 MPa para a região basal e valor de 30,0 MPa para a posição do topo conforme Tabela 1.

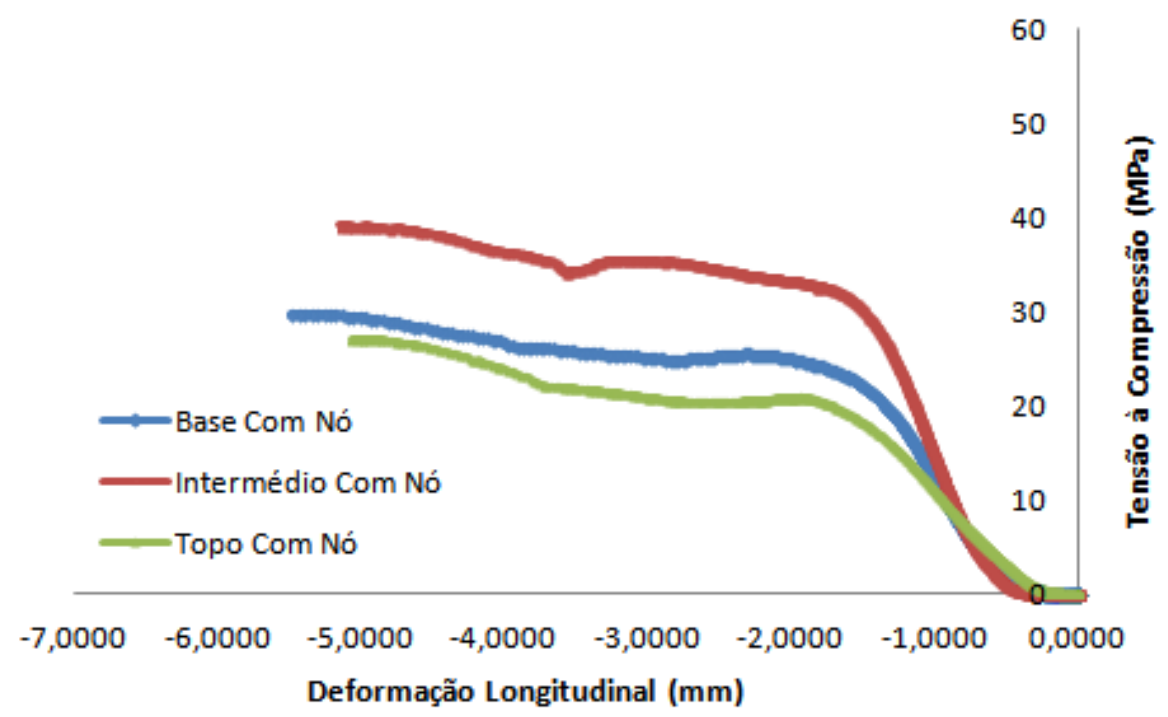

Figura 6 - Gráfico Tensão à Compressão x Deformação longitudinal (Amostras Com Nó)

Salienta-se que os valores apresentados nas Figuras 5 e 6 são amostrais, aproximando-se dos valores médios indicados na Tabela 1. 
Tabela 1 - Resultados de Resistência à compressão média do bambu Bambusa Vulgaris

\begin{tabular}{|c|c|c|c|c|c|}
\hline \multicolumn{2}{|c|}{$\begin{array}{c}\text { Posição } \\
\text { no colmo }\end{array}$} & $\begin{array}{c}\text { Resistência à } \\
\text { Compressão média (MPa) }\end{array}$ & $\begin{array}{c}\text { Desvio Padrão } \\
\text { (MPa) }\end{array}$ & $\begin{array}{c}\text { CV } \\
\text { (\%) }\end{array}$ & $\begin{array}{c}\text { Teor de umidade } \\
\text { (\%) }\end{array}$ \\
\hline \multirow{2}{*}{ Base } & Com nó & 32,5 & 6,1 & 18,7 & 16,2 \\
\cline { 2 - 6 } & Sem nó & 37,0 & 12,1 & 32,7 & 12,0 \\
\hline \multirow{2}{*}{ Intermédio } & Com nó & 33,4 & 7,9 & 23,8 & 16,0 \\
\cline { 2 - 6 } & Sem nó & 42,5 & 3,0 & 7,2 & 11,7 \\
\hline \multirow{2}{*}{ Topo } & Com nó & 30,0 & 4,3 & 14,3 & 16,5 \\
\cline { 2 - 6 } & Sem nó & 48,2 & 1,4 & 2,9 & 12,4 \\
\hline \multirow{2}{*}{ Valores médios } & 37,3 & 5,8 & 16,6 & 14,1 \\
\hline
\end{tabular}

Foram obtidos maiores valores de Resistência à Compressão paralela às fibras em amostras sem nó, as quais apresentaram teor de umidade médio conforme intervalo indicado pela ISO 22157:2019 (12\% $\pm 3 \%$ ). No entanto, foram verificados valores de umidade superiores ao descrito em norma para amostras com nó (indicado em vermelho), o que pode justificar a menor resistência à compressão para os corpos de prova situados no topo e com nó. Salgado Neto (2018) constata distinção na ruptura dos corpos de prova à compressão com e sem nó, onde se verificou propagação de aberturas no eixo longitudinal para amostras com presença de nós, sendo este considerado como ponto de fragilidade na direção longitudinal. Resultados similares ao presente estudo foram obtidos por Ghavami e Marinho (2005) para o bambu Guadua angustifolia, onde os valores à compressão variaram de 25,27 MPa para a região do topo sem nó e $31,77 \mathrm{MPa}$ para o topo com nó, obtendo valor médio de 29,48 MPa.

A Figura 7 apresenta o gráfico de Tensão ao Cisalhamento em relação à Deformação longitudinal para amostras sem nó, onde se observam maiores valores de tensão ao cisalhamento e deformações para a região intermediária, obtendo-se valor máximo de tensão média igual a 5,1 MPa. Constatou-se resistência ao cisalhamento médio de 3,7 MPa para a região basal e 3,1 MPa para a posição do topo conforme Tabela 2.

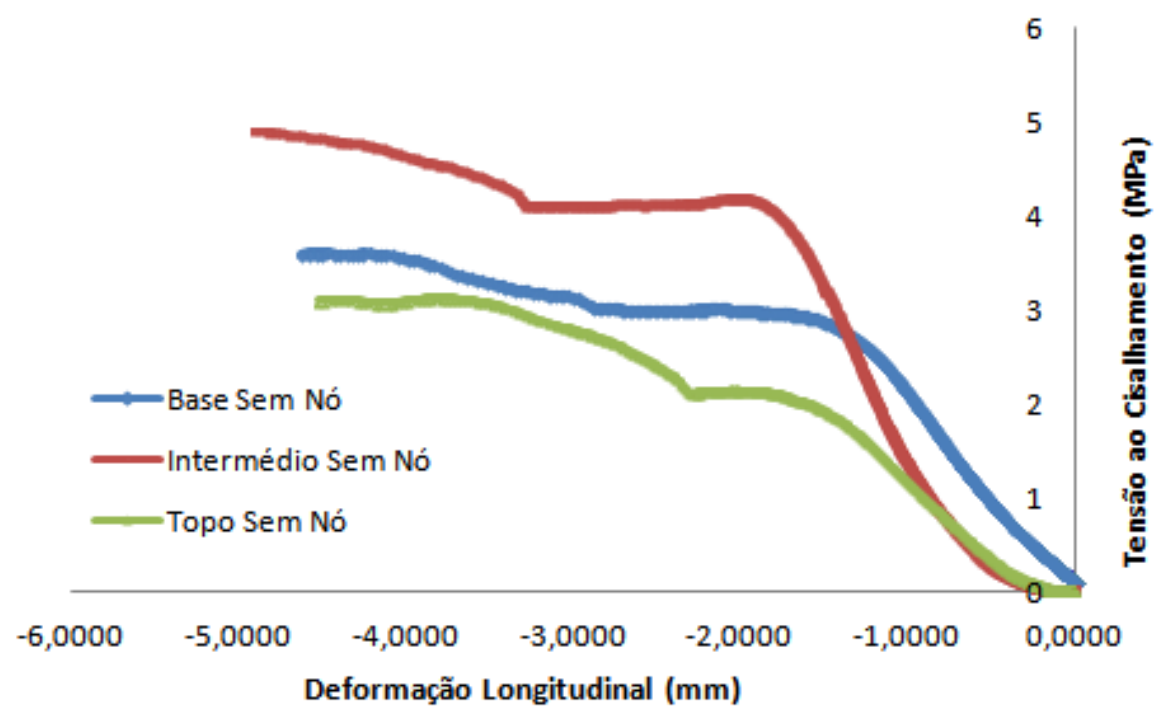

Figura 7 - Gráfico Tensão ao Cisalhamento x Deformação longitudinal (Amostras Sem Nó)

O gráfico de Tensão ao Cisalhamento em relação à Deformação longitudinal para amostras com nó é apresentado na Figura 8, onde se observam maiores valores de tensão ao cisalhamento e deformações para a região da base, obtendo-se valor máximo de tensão média igual a 4,6 MPa. Constatou-se resistência 
ao cisalhamento médio de 3,4 MPa para a região do topo e valor de 3,5 MPa para a posição intermediária conforme Tabela 2.

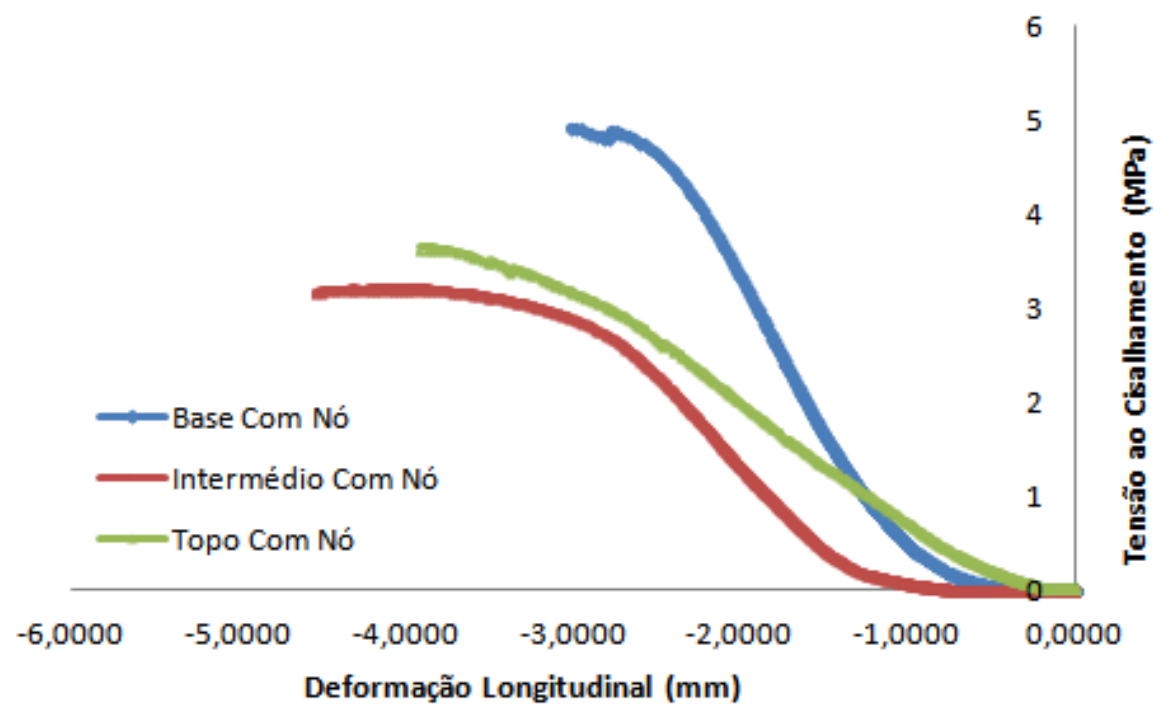

Figura 8 - Gráfico Tensão ao Cisalhamento x Deformação longitudinal (Amostras Com Nó)

Salienta-se que os valores apresentados nas Figuras 7 e 8 são amostrais, aproximando-se dos valores médios indicados na Tabela 2.

Tabela 2 - Resultados de Resistência ao cisalhamento médio do bambu Bambusa Vulgaris

\begin{tabular}{|c|c|c|c|c|c|c|}
\hline \multicolumn{2}{|c|}{$\begin{array}{c}\text { Posição } \\
\text { no colmo }\end{array}$} & $\begin{array}{c}\text { Resistência ao } \\
\text { Cisalhamento } \\
\text { médio (MPa) }\end{array}$ & $\begin{array}{c}\text { Desvio Padrão } \\
\text { (MPa) }\end{array}$ & $\begin{array}{c}\text { CV } \\
\text { (\%) }\end{array}$ & $\begin{array}{c}\text { Número de } \\
\text { Áreas Cisalhadas }\end{array}$ & $\begin{array}{c}\text { Teor de } \\
\text { umidade } \\
\text { (\%) }\end{array}$ \\
\hline \multirow{2}{*}{ Base } & Com nó & 4,6 & 0,8 & 17,3 & 4,0 & 15,0 \\
\cline { 2 - 7 } & Sem nó & 3,7 & 0,4 & 10,0 & 2,0 & 12,1 \\
\hline \multirow{3}{*}{ Intermédio } & Com nó & 3,5 & 0,8 & 23,6 & 2,0 & 14,3 \\
\cline { 2 - 7 } & Sem nó & 5,1 & 0,3 & 5,8 & 1,0 & 11,6 \\
\hline \multirow{2}{*}{ Topo } & Com nó & 3,4 & 0,5 & 14,0 & 3,0 & 14,5 \\
\cline { 2 - 7 } & Sem nó & 3,1 & 0,1 & 4,0 & 3,0 & 11,5 \\
\hline \multicolumn{2}{|c|}{ Valores médios } & 3,9 & 0,5 & 12,5 & 3,0 & 13,2 \\
\hline
\end{tabular}

Foram obtidos maiores valores de Resistência ao Cisalhamento em amostras com nó para as regiões basal e topo, e sem nó para a posição intermediária. Todas as médias apresentaram teor de umidade médio conforme intervalo indicado pela ISO 22157:2019 (12\% \pm 5\%), sendo observada maior umidade para amostras com nó. Os resultados obtidos, no presente estudo, para a resistência ao cisalhamento foram superiores aos apresentados por Ghavami e Marinho (2005) para o bambu Guadua angustifolia, onde os valores de resistência ao cisalhamento variaram de 2,42 MPa para a região do topo sem nó e 1,43 $\mathrm{MPa}$ para o intermédio com nó, obtendo valor médio de 2,02 MPa. 


\section{Conclusões}

Através deste estudo foi realizada a caracterização do bambu de espécie Bambusa Vulgaris quanto às propriedades mecânicas. Após a execução das etapas preliminares, foram executados os ensaios de caracterização mecânica do bambu da espécie Bambusa Vulgaris, sendo realizada uma análise comparativa entre os valores de resistência à compressão e ao cisalhamento paralelo às fibras em diferentes posições do colmo (Base, Intermédio e Topo), na presença ou ausência de nós, visando indicar a utilização do bambu B. Vulgaris como material alternativo à construção civil.

Foram obtidos maiores valores de resistência à compressão paralela às fibras em amostras sem nó (37,0 $\mathrm{MPa}, 42,5 \mathrm{MPa}$ e 48,2 Mpa para as posições basal, intermédio e topo, respectivamente). No ensaio de resistência ao cisalhamento paralela às fibras foram obtidos maiores valores de resistência em amostras com nó para as regiões basal (4,6 MPa) e topo $(3,4 \mathrm{MPa})$, e sem nó para a posição intermediária $(5,1 \mathrm{MPa})$.

Os resultados de caracterização mecânica demonstram o potencial do bambu aplicado à construção civil, sendo obtidos valores de resistência à compressão média de 37,3 MPa e resistência ao cisalhamento médio na ordem de 3,9 MPa, comparativos ao concreto convencional com resistência à compressão de 32,0 $\mathrm{MPa}$ e resistência ao cisalhamento de 7,0 MPa.

\section{Referências Bibliográficas}

Castelo Branco, L. M. (2016). Produção de mudas a partir de rizomas de bambusa vulgaris sob irrigação com água salina. Diss. Dissertação de Mestrado. Programa de Pós-Graduação em Engenharia Agrícola. Universidade Federal do Ceará, Fortaleza, CE.

Embrapa (2018). Bambu é alternativa de renda na produção familiar. Disponível em: https://www.embrapa.br/busca-de-noticias/-/noticia/34230725/bambu-e-alternativa-de-renda-naproducao-familiar. Acesso em: 19 nov. de 2020.

Ghavami, K.; Marinho, A. B. (2005). Propriedades físicas e mecânicas do colmo inteiro do bambu da espécie Guadua angustifolia. Revista Brasileira de engenharia agrícola e ambiental, Vol. 9.1: 107-114.

Ghavami, K.; Toledo Filho, R. D. (1992). Desenvolvimento de Materiais de Construção de Baixo Consumo de Energia usando Fibras Naturais, Terra e Bambu. Revista Brasileira de Engenharia Agrícola, Publicação Sociedade Brasileira de Engenharia Agrícola. Vol.2 (1), p. 1-19.

Padovan, R. B. (2010). O bambu na arquitetura: design de conexões estruturais. Diss. Dissertação de Mestrado. Programa de Pós-graduação em Design da Faculdade de Arquitetura, Artes e Comunicação. Universidade Estadual Paulista Júlio de Mesquita Filho, Bauru, SP.

Ribas, R. P. (2015). Bambu: Planta de Grande Potencial no Desenvolvimento Sustentável. Disponível em: https://mac.arq.br/wp-content/uploads/2016/03/bambu-desenvolvimento-sustentavel.pdf Acesso em: 20 nov. de 2020.

Salgado Neto, F. S. (2018). Análise Mecânica e Microestrutural da Interação do Bambu com o Concreto. Diss. Dissertação de Mestrado. Programa de Pós-Graduação em Engenharia Civil. Universidade Federal da Pará, Belém, PA.

Silva, I. C. (1985). Propagação vegetativa; aspectos morfo-fisiológicos. Boletim técnico. Belém, CEPLAC/DEPEA.

Silva, J. C. B. V; Lima, N.; Oliveira, V. M. (2011). Estufa ecológica: uso do bambu em bioconstruções. Centro Paranaense de Referência em Agroecologia - CPRA, Curitiba. 32 p. 